\title{
Cyanopeptide Co-Production Dynamics beyond Mirocystins and Effects of Growth Stages and Nutrient Availability
}

\author{
Regiane Natumi and Elisabeth M.-L. Janssen*
}

Cite This: Environ. Sci. Technol. 2020, 54, 6063-6072

Read Online

ABSTRACT: Intensified cyanobacterial bloom events are of increasing global concern because of adverse effects associated with the release of bioactive compounds, including toxic cyanopeptides. Cyanobacteria can produce a variety of cyanopeptides, yet our knowledge about their abundance and co-production remains limited. We applied a suspect-screening approach, including 700 structurally known cyanopeptides, and identified 11 cyanopeptides in Microcystis aeruginosa and 17 in Dolichospermum flos-aquae. Total cyanopeptide concentrations ranged from high nmol to $\mu \mathrm{mol} \mathrm{g}_{\mathrm{dry}}{ }^{-1}$ with slightly higher cell quotas in the mid-exponential growth phase. Relative cyanopeptide profiles were unchanged throughout the growth cycle. We demonstrate that quantification based on microcystin-LR equivalents can

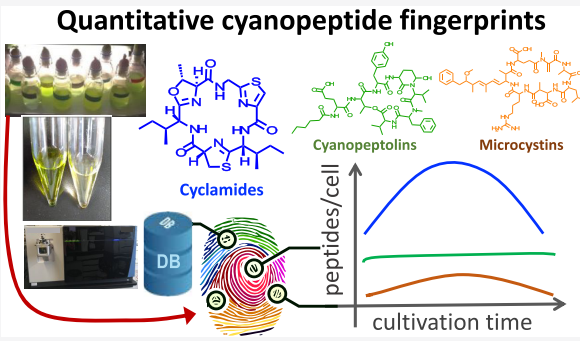
introduce an error of up to 6-fold and recommend a class-equivalent approach instead. In M. aeruginosa, rarely studied cyclamides dominated $(>80 \%)$ over cyanopeptolins and microcystins. While all nutrient reductions caused less growth, only lowering phosphorous and micronutrients reduced cyanopeptide production by $M$. aeruginosa. Similar trends were observed for $D$. flos-aquae and only lowering nitrogen decreased cyanopeptide production while the relative abundance of individual cyanopeptides remained stable. The synchronized production of other cyanopeptides along with microcystins emphasizes the need to make them available as reference standards to encourage more studies on their occurrence in blooms, persistence, and potential toxicity.

\section{INTRODUCTION}

Cyanobacterial blooms are a global challenge for freshwater ecosystems because they are detrimental to water quality. Bloom events can compromise recreational activities and are also considered a growing public health concern due to the production of toxins. ${ }^{1,2} \mathrm{~A}$ global increase in frequency and intensity of cyanobacterial blooms is in part related to increasing nutrient input and changing climate conditions (e.g., longer-lasting warm temperature periods, changes in hydrological mixing, etc.). ${ }^{3}$ This increase has prompted the interest of scientists and water managers to elucidate the factors controlling not only proliferation of cyanobacteria but also production of their bioactive metabolites that are potentially toxic.

Numerous studies have been conducted in the past decade regarding the occurrence of microcystins, one class of cyanopeptides that has been classified as hepatotoxic and has been linked to animal poisoning and even human fatalities. ${ }^{4-7}$ Consequently, water quality guidelines have been included in risk management frameworks of the WHO focusing on microcystin-LR, the most frequently reported variant of more than 200 known microcystins. ${ }^{8}$ However, besides the wellknown class of microcystins, cyanobacteria produce a variety of cyanopeptides, which can be classified by structural similarities, including cyclamides, cyanopeptolins, aeruginosins, anabaenopeptins, and microginins. Over the past few decades, hundreds of cyanopeptides have been identified in pure cultures and biomass collected from cyanobacterial bloom events. ${ }^{9-11}$
Genotype analysis supports the presence of biosynthesis genes for cyanopeptides beyond microcystins in common cyanobacterial species, including Microcystis, Dolichospermum, and Planktothrix. ${ }^{12,13}$ While the potential to produce cyanopeptides beyond microcystins is widely accepted, our knowledge about their abundance, persistence, and toxicity remains largely limited.

One limiting factor regarding our knowledge about these understudied cyanopeptides is the lack of commercially available reference standard materials that are essential for fate and toxicity studies and routine analytical measurements. Alternatively, most studies thus far report only qualitative information or semiquantitative concentrations based on microcystin-LR equivalent units, as this reference material is commercially available. ${ }^{14-17}$ Two recent studies used up to six purified cyanopeptolins, microginins, and anabaenopeptins to quantify them directly in lake water from cyanobacterial blooms. ${ }^{10,18,19}$ These studies demonstrated that other cyanopeptides can occur in high frequency and comparable concentrations to microcystins and can even reach drinking

Received: December 3, 2019

Revised: April 16, 2020

Accepted: April 17, 2020

Published: April 17, 2020

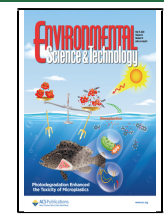


water treatment plants. ${ }^{20}$ However, the availability of such reference standards remains restricted and monitoring only single cyanopeptides can still underestimate exposure to other potentially toxic metabolites during cyanobacterial bloom events. Most studies include only these few cyanopeptides for which reference standards exist but without verifying that these are the most abundant peptides present in the bloom of species of interest. A better understanding of other cyanopeptides would facilitate the prioritization of those compounds for which reference standards need to be made available.

The concentration of cyanopeptides in surface waters defines the exposure side of the risk equation and is typically correlated with the cell abundance of toxin-producing cyanobacteria. Microcystin concentrations were observed to peak in the mid-exponential growth period for Microcystis sp. and Dolichospermum sp. (previously Anabaena). ${ }^{21,22}$ Single studies observed similar production dynamics for anabaenopeptins, cyanopeptolins (i.e., anabaenopeptilides), and microginins. ${ }^{17,22,23}$ Cyanobacterial growth and microcystin production can be affected by environmental variables, including light intensities, temperature, $\mathrm{pH}$, and in particular nutrient availability, which we focus on herein. ${ }^{23,24}$ Nitrogen, phosphorus, and micronutrients are essential elements for cellular functioning and nitrogen itself is also a main molecular component of (cyano)peptides. ${ }^{24}$ Cyanobacterial taxa cope differently with limited nutrient availability. Microcystis and Dolichospermum generally thrive well at high phosphate concentrations, and the nitrogen-fixing Dolichospermum are also associated with lower nitrogen concentrations. ${ }^{25-28}$ Regarding production dynamics of toxins, most research thus far focused on microcystins. Changes in nitrogen and phosphorous availability affected the regulation of $m c y$ gene expression, total microcystin production, microcystin cell quota, ratios of toxin-producing versus nonproducing cyanobacteria, and varied among different strains of Microcystis. $^{29-36}$ Our knowledge on the co-production dynamics of these other cyanopeptides remains sparse, and only a few studies inspected effects on cyanopeptide production beyond microcystins thus far. ${ }^{17,22,23}$ Understanding whether the production dynamics are synchronized or independent among different cyanopeptides and how nutrient availability influences their presence across growth stages is not only essential for predicting exposure concentrations but may also shed light on the underlying drivers for cyanobacteria to produce such a complex and metabolically expensive peptides in the first place.

In the presented study, we applied a suspect-screening approach to monitor the co-production dynamics of cyanopeptides across different growth stages and nutrient conditions, including phosphorous, nitrogen, and micronutrient reduction for Microcystis aeruginosa and Dolichospermum flos-aquae. Our results demonstrate that the production of all cyanopeptides was synchronized in $M$. aeruginosa also for the rarely studied but dominating cyclamides. Abundant cyanopeptides likely co-occur at different growth stages and nutrient conditions and reference standards should be made available in the future to include them in lake monitoring, fate studies, and toxicity testing.

\section{EXPERIMENTAL SECTION}

Materials. Microcystin reference standards for MC-LR, MC-YR, MC-RR, MC-LF, MC-LA, MC-LW, MC-LY, and
Nodularin were obtained from Enzo Life Science (Lausen, Switzerland). Cyanopeptolin A, cyanopeptolin D, anabaenopeptin A, anabaenopeptin NZ857, and oscillamide $\mathrm{Y}$ were obtained as bioreagents from CyanoBiotech $\mathrm{GmbH}$ (Berlin, Germany). Aerucyclamide A was obtained as a purified bioreagent in dimethyl sulfoxide by Prof. Karl Gademann (University Zurich, Switzerland). ${ }^{37}$ Additional materials are listed in the Supporting Information.

Cyanobacterial Cultures. M. aeruginosa PCC7806 was originally isolated from the Braakman reservoir in The Netherlands (1972) and was obtained from the Pasteur Culture Collection of Cyanobacteria (France). D. flos-aquae NIVA-CYA 269/6 was originally isolated from Lake Frøylandsvatnet in Norway (1990) and was obtained from the Norwegian Culture Collection of Algae (NORCCA). We maintained cultures in $100 \mathrm{~mL}$ Erlenmeyer flasks in modified WC medium (Table S1) at $20 \pm 2{ }^{\circ} \mathrm{C}$ and irradiance at 12 $\mu \mathrm{mol}$ photons $\mathrm{m}^{-2} \mathrm{~s}^{-1}$ on a $12: 12 \mathrm{~h}$ light/dark cycle. ${ }^{38}$ Before using in an experiment, cultures were maintained in the respective medium over two inoculation cycles where $10-15 \%$ inoculum was transferred to fresh medium every three weeks at the later stage of the exponential growth phase. All subculturing and sampling in the experiments described below were performed under sterile conditions.

Effects of Growth Stages and Nutrients. The effects of the growth stage and nutrient concentrations on cyanopeptide production and cell density were evaluated for M. aeruginosa. Cultures were prepared in duplicate in $1 \mathrm{~L}$ Schott bottles with $800 \mathrm{~mL}$ medium and an initial cell density of $(1-3) \times 10^{5}$ cells $\mathrm{mL}^{-1}$. The cultures were kept under continuous aeration. In addition to the standard conditions of the WC medium with a nitrogen to phosphorous ratio of $\mathrm{N} / \mathrm{P}=20\left(1 \mathrm{mmol} \mathrm{N} \mathrm{L}^{-1}\right.$, $\left.0.05 \mathrm{mmol} \mathrm{P} \mathrm{L}{ }^{-1}\right)$, the effect of increasing phosphorus 10 -fold $(\mathrm{N} / \mathrm{P}=2)$ and decreasing phosphorus by factor $2(\mathrm{~N} / \mathrm{P}=40)$ were investigated across the growth curve. For cyanopeptide analysis, $15 \mathrm{~mL}$ of each bottle was sampled on days 0 and 3, 10 $\mathrm{mL}$ on day 6 , and $5 \mathrm{~mL}$ for the remaining of the growth curve.

In addition, the cyanopeptide production in the late exponential phase was analyzed for $M$. aeruginosa and D. flosaquae to compare the cyanopeptide profiles between species and under additional nutrient conditions. The experiments were performed in triplicate in $250 \mathrm{~mL}$ Schott bottles containing $150 \mathrm{~mL}$ of WC medium with an initial cell density of (9.1-9.8) $\times 10^{4}$ and (9.0-9.6) $\times 10^{4}$ cells $\mathrm{mL}^{-1}$ for $M$. aeruginosa and D. flos-aquae, respectively. Besides the standard conditions in WC medium at $\mathrm{N} / \mathrm{P}=20\left(1 \mathrm{mmol} \mathrm{N} \mathrm{L} \mathrm{L}^{-1}, 0.05\right.$ mmol $\left.\mathrm{P} \mathrm{L} \mathrm{L}^{-1}\right), 5$ different nutrient compositions were investigated: 3-fold increase of phosphorus $(+\mathrm{P}, \mathrm{N} / \mathrm{P}=$ $6.66)$; decrease of phosphorus by factor $100(-\mathrm{P}, \mathrm{N} / \mathrm{P}=$ $2000)$; decrease of nitrogen by factor $100(-\mathrm{N}, \mathrm{N} / \mathrm{P}=0.2)$; decrease of both phosphorus and nitrogen by factor $100(-\mathrm{N}$ and $-\mathrm{P}, \mathrm{N} / \mathrm{P}=20)$; and decrease of micronutrients by factor 100 (-MN) (Table S1). The culture bottles were manually shaken periodically and rearranged randomly to reduce the effects of minor differences in the light field on the culturing shelf. For cyanopeptide analysis, $10 \mathrm{~mL}$ of culture was sampled when the cells reached the late exponential phase. In bottles with reduced micronutrients, sampling took place after 40 days as the culture only showed minimal growth during the experiment.

For all experiments, $2 \mathrm{~mL}$ was removed every $72 \mathrm{~h}$ to determine the number of cells by optical density at $750 \mathrm{~nm}$ (Cary Series UV-Vis Spectrophotometer, Agilent Technolo- 
gies). For the growth curve experiment, the cells were also counted using a Neubauer counting chamber under a light microscope (Leitz Biomed, magnification $\times 400$ ). At least 100 cells were counted for four subsamples and the average was reported and used to normalize cyanopeptide concentration. A calibration of cell count versus optical density at $750 \mathrm{~nm}$ for each nutrient condition was used to convert optical densities to cell numbers (Figure S1). The evolution of cell abundance over time was fit to the Richard model to evaluate the growth curves $^{39}$

$$
y(t)=A \cdot\left[1+\nu \cdot \exp \left(1+\nu+\frac{\mu}{A} \cdot(1+\nu)^{1+1 / \nu} \cdot(\lambda-t)\right)\right]^{(-1 / \nu)}
$$

with $y(t)$ being the cell density as log-normalized optical density, $\log \left(\mathrm{OD}_{t} / \mathrm{OD}_{0}\right)$, at time $t, \mu$ being the growth rate, $\lambda$ being the time of the lag phase, $A$ being the final cell density as maximum $\log \left(\mathrm{OD}_{t} / \mathrm{OD}_{0}\right)$, and $\nu$ being a shape parameter set to 1.8. The parameters $\mu$ and $\lambda$ were obtained from the fit resulting in the minimized sum of least square error (Solver function in Microsoft Excel, version 2010).

Cyanopeptide Extraction. The cells were harvested by centrifugation ( $\mathrm{rcf}$ of $4660 \mathrm{~g}$ at $10^{\circ} \mathrm{C}, 10 \mathrm{~min}$, Megafuge $1.0 \mathrm{R}$, Heraeus Instruments), lyophilized $\left(-40{ }^{\circ} \mathrm{C},-3 \mathrm{mbar}, 24 \mathrm{~h}\right.$, Lyovac GT2, Leybold), and stored at $-20{ }^{\circ} \mathrm{C}$ until further analysis. For extraction, the weight of the dry material was recorded and $\mathrm{MeOH} / \mathrm{H}_{2} \mathrm{O}(70: 30 \mathrm{v} / \mathrm{v})$ was added at a ratio of $5 \mu \mathrm{L} \mathrm{mg}$ dry,wt $^{-1}$. The suspension was homogenized by vortexing, incubated under sonication (VWR, Ultrasonic cleaner USC-THD, level 6, $10 \mathrm{~min}$ ), and solids were separated from the supernatant by centrifugation ( $\mathrm{rcf}$ of $4660 \mathrm{~g}, 10 \mathrm{~min}$ ). The supernatant was transferred to a new glass vial and the extraction was repeated two more times. The solvent was evaporated from the combined extract under a gentle stream of nitrogen $\left(40{ }^{\circ} \mathrm{C}\right.$, TurboVap $\mathrm{LV}$, Biotage $)$ to reduce the methanol content to less than $5 \%$. The extracts were diluted to a total volume of $3 \mathrm{~mL}$ with nanopure water prior to clean-up by solid-phase extraction (SPE) on a 12-fold vacuum extraction box (Visiprep, 12 ports, Sigma Aldrich). The SPE cartridges (Oasis HLB $3 \mathrm{cc}, 60 \mathrm{mg}$ ) were consecutively conditioned with methanol and water ( $9 \mathrm{~mL}$ each). The extracts were loaded onto the cartridges, washed with $9 \mathrm{~mL}$ of nanopure water followed by $9 \mathrm{~mL}$ of $\mathrm{MeOH} / \mathrm{H}_{2} \mathrm{O}(20: 80 \mathrm{v} / \mathrm{v})$ prior to elution with $9 \mathrm{~mL} \mathrm{MeOH} / \mathrm{H}_{2} \mathrm{O}(85: 15 \mathrm{v} / \mathrm{v})$ at a flow rate of $1 \mathrm{~mL} \mathrm{~min}{ }^{-1}$. The eluted fraction was collected and concentrated to $300 \mu \mathrm{L}$ by vacuum-assisted evaporation (Syncore Analyst R-12, BÜCHI Labortechnik AG, $40{ }^{\circ} \mathrm{C}$, $120 \mathrm{rpm}, 20 \mathrm{mbar})$. Each volume was adjusted gravimetrically to $1.0 \mathrm{~mL} \mathrm{MeOH} / \mathrm{H}_{2} \mathrm{O}(10: 90 \mathrm{v} / \mathrm{v})$ before analysis. Additionally, empty glass vials were extracted and the extracts were subjected to SPE clean up and concentration serving as method blanks. Cyanopeptide standards and bioreagents were spiked to nanopure water, and these samples were processed in the same manner to evaluate relative recoveries of the sample preparation steps (results in Tables S2 and S3).

Cyanopeptide Analysis. Peptide analysis was performed by high-performance liquid chromatography (Dionex UltiMate3000 RS pump, Thermo Fischer Scientific) with an autosampler (CTC Analytics) coupled to a high-resolution tandem mass spectrometer (HRMS/MS, Q-Exactive-Plus Orbitrap, ThermoFisher Scientific). Chromatographic separation was carried out on an XBridgeTM C18 column $(3.5 \mu \mathrm{m}$, $2.1 \mathrm{~mm} \times 50 \mathrm{~mm}$, Waters) with precolumn (VanGuard
Cartridge, Waters) and inline filter (BGB). The mobile phases consisted of nanopure water (eluent A) and methanol (eluent B), both acidified with formic acid (0.1\%). Binary gradient elution was carried out at a flow rate of $200 \mu \mathrm{L} \mathrm{min}$ min $^{-1}$ and increasing eluent B from 10 to $100 \%$ between 0 and $27.5 \mathrm{~min}$. The injection volume was $25 \mu \mathrm{L}$. Detection of analytes was achieved by HRMS/MS with electrospray ionization (ESI), $320{ }^{\circ} \mathrm{C}$ capillary temperature, $4 \mathrm{kV}$ electrospray voltage, and 35 $\mathrm{V}$ capillary voltage in a positive ionization mode. Full scan accurate mass spectra were acquired from 200 to $1500 \mathrm{~m} / z$ with a nominal resolving power of 140000 referenced at $\mathrm{m} / z$ 250 , automated gain control (AGC) of $1 \times 10^{6}$, and maximal injection time of $100 \mathrm{~ms}$ with $1 \mathrm{ppm}$ mass accuracy. Datadependent high-resolution product ion spectra were obtained by $\mathrm{HCD}$ at $35 \%$ collision energy, at a resolving power of 17500 at $400 \mathrm{~m} / z$, AGC of $1 \times 10^{5}$ and maximal injection time of $80 \mathrm{~ms}$. For triggering data-dependent MS/MS acquisition, we included an in-house suspect list as detailed in Table S4.

Data Processing. The suspect screening included 712 cyanopeptides in total with 297 microcystins, 149 cyanopeptolins, 38 anabaenopeptins, 18 cyclamides, 61 microginins, 55 cryptophycins, 50 aeruginosins, and 44 other compounds (Table S4). The identification of most cyanopeptides needed to be carried out without available reference standard materials. Thus, a comprehensive data analysis workflow adopted from suspect screening applied to small molecules was used. ${ }^{40}$ Spectral libraries do not exist for most suspects, and in silico fragmentation predictions were used to facilitate fragment identification (Mass Frontier 7.0, mMass 5.5.0). Herein, only those cyanopeptides were reported that could be identified as one of the following criteria. A compound was identified as a tentative candidate based on exact mass $(<5$ ppm mass error), accurate isotopic pattern (idotp $>0.9$ ), and evidence from the fragmentation data; cyanopeptides were identified as confirmed structures when these parameters were in agreement with available reference standards or bioreagents. The comparison of intensity over the $\mathrm{m} / \mathrm{z}$ range for mass spectrometry fragmentation spectra between confirmed structures (level 1) and cyanobacteria biomass extract was done by plotting head to tail plots using the $\mathrm{R}$ packages RMassBank $^{41}$ and MSMSsim ${ }^{42}$ (Figures S2-S10). Data analysis was performed in RStudio with $\mathrm{R}$ version 3.6.1. ${ }^{43}$ The HRMS measurement data files were converted to open.mzXML data format using the msconvert tool from ProteoWizard. ${ }^{44}$ The data evaluation and extraction of peak areas was performed with Skyline (version 4.1).

The peak area of the selected ion chromatogram was extracted for all identified cyanopeptides. Different charge states $(z=1, z=2)$ and adducts $(+\mathrm{H},+\mathrm{Na})$ were considered and for all identified compounds, the $\mathrm{M}+\mathrm{H}$ was identified as the dominant ion with the exception of microcystins that contain two arginine moieties, here the $\mathrm{M}+2 \mathrm{H}$ was selected for area extraction. The identified cyanopeptides were quantified by external calibration curves of the available reference standard and bioreagent in the range of the analyte concentration present in the samples. Matrix effects on ionization efficiency were considered by standard addition to cyanobacterial extracts. Concentrations were only reported when the peak area was above the limits of quantification (LOQs), defined as 10 times the ratio of the standard deviation of the response-to-slope of the calibration curve. Parameters for matrix effects, relative response factor, LOD, 
Table 1. Main Cyanopeptides Tentatively Identified in Cell Extracts of M. aeruginosa and D. flos-aquae

\begin{tabular}{|c|c|c|c|c|}
\hline cyanopeptide & references & molecular formula & class equivalents $^{a}(\%)$ & MC-LR equivalents ${ }^{b}(\%)$ \\
\hline \multicolumn{5}{|l|}{ Microcystis aeruginosa } \\
\hline aerucyclamide A & 37 & $\mathrm{C}_{24} \mathrm{H}_{34} \mathrm{~N}_{6} \mathrm{O}_{4} \mathrm{~S}_{2}$ & $43 \pm 10$ & $33 \pm 9$ \\
\hline aerucyclamide $\mathrm{C}$ & 37 & $\mathrm{C}_{24} \mathrm{H}_{32} \mathrm{~N}_{6} \mathrm{O}_{5} \mathrm{~S}$ & $25 \pm 6$ & $19 \pm 5$ \\
\hline aerucyclamide B & 48 & $\mathrm{C}_{24} \mathrm{H}_{32} \mathrm{~N}_{6} \mathrm{O}_{5} \mathrm{~S}_{2}$ & $11 \pm 3$ & $9 \pm 2$ \\
\hline aerucyclamide D & 48 & $\mathrm{C}_{26} \mathrm{H}_{30} \mathrm{~N}_{6} \mathrm{O}_{4} \mathrm{~S}_{3}$ & $3 \pm 1$ & $2 \pm 1$ \\
\hline total aerucyclamides & & & $82 \pm 12$ & $63 \pm 11$ \\
\hline MC-LR & 49 & $\mathrm{C}_{49} \mathrm{H}_{74} \mathrm{~N}_{10} \mathrm{O}_{12}$ & $3 \pm 1$ & $10 \pm 3$ \\
\hline MC-LR-demethyl group ${ }^{c}$ & & $\mathrm{C}_{48} \mathrm{H}_{72} \mathrm{~N}_{10} \mathrm{O}_{12}$ & $1 \pm<1$ & $6 \pm 2$ \\
\hline total microcystins & & & $4 \pm 1$ & $16 \pm 4$ \\
\hline cyanopeptolin D & 45 & $\mathrm{C}_{48} \mathrm{H}_{76} \mathrm{~N}_{8} \mathrm{O}_{12}$ & $5 \pm 1$ & $7 \pm 3$ \\
\hline cyanopeptolin A & 45 & $\mathrm{C}_{46} \mathrm{H}_{71} \mathrm{~N}_{10} \mathrm{O}_{12} \mathrm{H}$ & $4 \pm 1$ & $8 \pm 3$ \\
\hline cyanopeptolin C & 45 & $\mathrm{C}_{47} \mathrm{H}_{73} \mathrm{~N}_{8} \mathrm{O}_{12} \mathrm{H}$ & $3 \pm 1$ & $3 \pm 2$ \\
\hline cyanopeptolin B & 45 & $\mathrm{C}_{46} \mathrm{H}_{71} \mathrm{~N}_{8} \mathrm{O}_{12} \mathrm{H}$ & $1 \pm<1$ & $3 \pm 1$ \\
\hline total cyanopeptolins & & & $14 \pm 2$ & $21 \pm 5$ \\
\hline \multicolumn{5}{|l|}{ Dolichospermum flos-aquae } \\
\hline oscillamide Y & 50 & $\mathrm{C}_{45} \mathrm{H}_{59} \mathrm{~N}_{7} \mathrm{O}_{10}$ & $84 \pm 23$ & $33 \pm 8$ \\
\hline anabaenopeptin A & 51 & $\mathrm{C}_{44} \mathrm{H}_{57} \mathrm{~N}_{7} \mathrm{O}_{10}$ & $7 \pm 2$ & $22 \pm 5$ \\
\hline 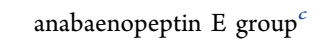 & & $\mathrm{C}_{42} \mathrm{H}_{62} \mathrm{~N}_{10} \mathrm{O}_{9}$ & $2 \pm<1$ & $10 \pm 2$ \\
\hline anabaenopeptin B & 52 & $\mathrm{C}_{41} \mathrm{H}_{60} \mathrm{~N}_{10} \mathrm{O}_{9}$ & $1 \pm<1$ & $7 \pm 1$ \\
\hline total anabaenopeptins & & & $94 \pm 23$ & $72 \pm 10$ \\
\hline MC-YR-group ${ }^{c}$ & & $\mathrm{C}_{52} \mathrm{H}_{72} \mathrm{~N}_{10} \mathrm{O}_{13}$ & $2 \pm<1$ & $8 \pm 1$ \\
\hline MC-LR-demethyl group ${ }^{c}$ & & $\mathrm{C}_{48} \mathrm{H}_{72} \mathrm{~N}_{10} \mathrm{O}_{12}$ & $2 \pm<1$ & $7 \pm 1$ \\
\hline MC-LR & 49 & $\mathrm{C}_{49} \mathrm{H}_{74} \mathrm{~N}_{10} \mathrm{O}_{12}$ & $1 \pm<1$ & $3 \pm<1$ \\
\hline MC-HtyR group ${ }^{b}$ & 53,54 & $\mathrm{C}_{53} \mathrm{H}_{74} \mathrm{~N}_{10} \mathrm{O}_{13}$ & $1 \pm<1$ & $4 \pm<1$ \\
\hline total microcystins & & & $6 \pm<1$ & $22 \pm 2$ \\
\hline
\end{tabular}

${ }^{a}$ Quantitative analysis based on selected positive ion chromatograms of the protonated peptides. Relative amounts of variants smaller than two percent of the total were not included. Quantification was based on class equivalent ( $\mathrm{mol} \mathrm{mg}^{-1}$ dry weight of biomass). ${ }^{b}$ Quantification was based on Microcystin-LR equivalents. ${ }^{c}$ Isobaric compounds, see Table S7.

LOQ and recoveries from sample preparation can be found in Table S2. For those cyanopeptides for which no reference standard or bioreagent was available, we calculated microcystin-LR equivalent units and class-specific equivalents. The microcystin-LR equivalent units were calculated from external calibration with microcystin-LR standard. To calculate the class-specific equivalent units, we calculated the response factor of the calibration slope for all available bioreagents relative to that of microcystin-LR. We multiplied the microcystin-LR equivalent units for each compound by the relative response factor of the structurally most similar bioreagent or standard. All (equivalent) concentrations were normalized either to the number of cells or the dry weight of extracted biomass. The independent student $t$-test and one-way analysis of variance (ANOVA) followed by Tukey was employed to detect any statistically significant difference in the total cyanopeptide concentration, growth rate, and final cell density by comparison of the $95 \%$ confidence intervals $(\alpha=0.05)$ in RStudio (version 3.6.1).

\section{RESULTS AND DISCUSSION}

Co-Production of Cyanopeptides. We investigated the co-production of cyanopeptides in $M$. aeruginosa and D. flosaquae by suspect screening of 712 structurally known cyanobacterial peptides, including cyclamides, cyanopeptolins, aeruginosins, microcystins, anabaenopeptins, and microginins. Of these, we tentatively identified 11 cyanopeptides in $M$. aeruginosa and 17 in D. flos-aquae, and the most abundant metabolites are listed in Table 1 (for compounds with $<2 \%$ abundance, see Tables S5 and S6). We observed a total cyanopeptide concentration of $0.4 \pm 0.1 \mu \mathrm{mol} \mathrm{g} \mathrm{dry}_{\text {-wt }}^{-1}$ in $M$. aeruginosa and $2.0 \pm 0.4 \mu \mathrm{mol} \mathrm{g}_{\text {dry-wt }}{ }^{-1}$ in $D$. flos-aquae for biomass harvested in the late exponential growth phase (WC medium with N/P 20). Since standard reference materials were not available for most cyanopeptides, we used a classequivalent approach for quantification (Tables S5 and S6). The response factors varied up to 2.5-fold across different microcystin variants and up to 6-fold across all cyanopeptides tested. The class-equivalent approach critically affected quantification compared to microcystin-LR equivalents. For example, the class-equivalent concentrations for cyanopeptolin $A$ and aerucyclamide A were 2.3- and 6-fold higher, respectively, compared to microcystin-LR equivalent units. As long as no true reference materials are available for each compound, we recommend quantification by class equivalents instead of microcystin-LR equivalents.

Based on class-equivalent quantification, cyclamides contributed $82 \%$, cyanopeptolins $14 \%$, and microcystins $4 \%$ to the total cyanopeptide pool of $M$. aeruginosa. The class of cyclamides was dominated by aerucyclamide $\mathrm{A}$, followed by aerucyclamide $\mathrm{C}, \mathrm{B}$, and $\mathrm{D}$, which are all cyclic hexapeptides characterized by three azole or azoline rings. The sulfoxide of aerucyclamide $\mathrm{D}$ was also detected, which can be formed upon post-translational methionine oxidation. Aerucyclamide A was with $43 \%$ most abundant cyanopeptide overall and has, to our current knowledge, not been included in the studies of production dynamics to date. The class of cyanopeptolins was dominated by cyanopeptolin D followed by cyanopeptolin A, $\mathrm{C}$, and $\mathrm{B}$. Cyanopeptolins are depsipeptides containing the characteristic 3-amino-6-hydroxy-2-piperidone (Ahp) moiety and the four variants differ in one of the six building blocks, where the $\mathrm{N}, \mathrm{N}$-dimethyl-lysine of cyanopeptolin $\mathrm{D}$ is replaced 
by arginine, $N$-methyl-lysine, or lysine, respectively. ${ }^{45-47}$ The class of microcystins was dominated by microcystin-LR, followed by the demethyl-microcystin-LR-group. Note that the demethyl-microcystin-LR-group represents isobaric compounds with $\mathrm{C}_{48} \mathrm{H}_{72} \mathrm{~N}_{10} \mathrm{O}_{12}$. Details of all isobaric groups reported herein can be found in Table S7. Overall, the abundant cyanopeptides observed here are comparable to a recent report on the global metabolome of bloom-forming Microcystis spp. ${ }^{14}$

In D. flos-aquae, anabaenopeptins contributed $94 \%$ and microcystins $6 \%$ to the total cyanopeptide pool based on class equivalents. The class of anabaenopeptins was dominated by oscillamide $\mathrm{Y}(83 \%)$ and a smaller contribution of anabaenopeptin A (7\%), the isobaric group of anabaenopeptin E $\left(2 \%, \mathrm{C}_{42} \mathrm{H}_{62} \mathrm{~N}_{10} \mathrm{O}_{9}\right.$ see Table S6) and anabaenopeptin $\mathrm{B}$ (1\%). We confirmed the presence of oscillamide $\mathrm{Y}$ and not its isobaric analogue anabaenopeptin NZ857 by analysis of the secondary fragmentation (see Figures S6 and S7). Anabaenopeptins are five-membered cyclic peptides with the ureido bond connecting the primary amine of lysine with the primary amine of the neighboring amino acid and lysine's epsilonamine with the carboxyl group of the $C$ terminal amino acid to form a urea moiety. Oscillamide $\mathrm{Y}$ and anabaenopeptin $\mathrm{A}$ contain, respectively, an L-Phe and L-Tyr, which is replaced for L-Arg in the anabaenopeptin B and E group. Additional variation is mostly attributed to changes in the aliphatic parts. The class of microcystins was dominated by microcystin-YR (2\%), followed by the demethyl-microcystin-LR-group (2\%) and microcystin-LR (1\%). We further evaluated the cyanopeptide production dynamics along the growth curve and then compared cyanopeptide profiles under different nutrient conditions.

Production Dynamics along the Growth Curve. We investigated the change of peptide production relative to cell abundance and across the growth phases of M. aeruginosa in batch cultures. We used three different initial phosphorous concentrations of $0.5,0.05$, and $0.025 \mathrm{mmol} \mathrm{L}^{-1}$ while the initial nitrogen content was kept constant at $1 \mathrm{mmol} \mathrm{L}^{-1}$ resulting in N/P ratios of 2, 20, and 40, respectively. Previous studies reported that extracellular concentrations typically account for a small fraction of the total cyanopeptide pool, even in the stationary phase when the release of intracellular peptides into the medium can be higher due to cell lysis; hence, we focused on intracellular cyanopeptide concentrations herein. $^{55,56}$

Data in Figure 1A show the growth curve of M. aeruginosa as normalized cell abundance and the growth behavior was comparable under the three $\mathrm{N} / \mathrm{P}$ conditions with slightly lower total final cell abundance in the $0.5 \mathrm{mmol} \mathrm{L}^{-1}$ conditions (nonnormalized data Figure S11). Microcystis have been shown to grow equally well with comparable growth rates across a wide range of phosphorus concentrations $\left(1.75 \mu \mathrm{mol} \mathrm{L}^{-1}\right.$ to $2 \mathrm{mmol}$ $\left.\mathrm{L}^{-1}\right){ }^{57,58}$ Data in Figure $1 \mathrm{~B}$ show that the concentration of total cyanopeptides $\left(\mathrm{nmol} \mathrm{mL} \mathrm{mL}^{-1}\right)$ directly correlated with cell abundance and the cyanopeptide production per cell remained stable between 0.025 and $0.5 \mathrm{mmol} \mathrm{P} \mathrm{L} \mathrm{L}^{-1}$. The correlation of cyanobacteria biovolume and microcystin production has been regularly reported. ${ }^{25,59,60}$ These observations were supported by the fact that the mcyD gene, one of the genes involved in microcystin biosynthesis, was upregulated in M. aeruginosa when phosphorus concentration was decreased in batch cultures. ${ }^{58}$ Here, we demonstrate that the correlation also holds for the production dynamics of other cyanopeptides,
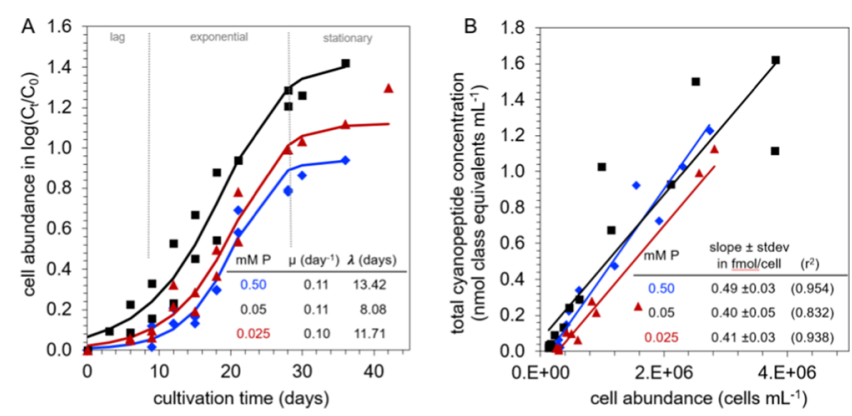

Figure 1. (A) Growth curves of M. aeruginosa as log-normalized cell abundance $\left(\log C_{t} / C_{0}\right)$ for batch experiments in a medium with 1 mmol L $\mathrm{L}^{-1}$ nitrogen and at three total phosphorous concentrations being $0.50 \mathrm{mmol} \mathrm{L}^{-1}(\mathrm{~N} / \mathrm{P}=2), 0.05 \mathrm{mmol} \mathrm{L}^{-1}(\mathrm{~N} / \mathrm{P}=20)$, and $0.025 \mathrm{mmol} \mathrm{L}^{-1}(\mathrm{~N} / \mathrm{P}=40)$. The growth parameters $\mu$ being the exponential growth rate per day and $\lambda$ being the lag time before exponential growth in days were obtained by fitting to the Richard model and are listed in the insert. (B) Total cyanopeptide concentrations in $\mathrm{nmol} \mathrm{mL} \mathrm{m}^{-1}$ cyanopeptide class equivalence relative to total cell abundance. The slope represents the cyanopeptide production rate in fmol per cell and parameters of the linear regression are listed in the insert.

including cyclamides and cyanopeptolins, that were coproduced (Figure S12). Even though the other cyanopeptide classes are synthetized by different gene clusters, these findings raise the question of whether the production dynamics of less studied cyanopeptides are regulated in a similar manner to microcystins.

We further investigated cyanopeptide production dynamics across the growth phases. Data in Figure 2 show the cyanopeptide concentrations per cell across the growth phases at an initial phosphorous concentration of $0.05 \mathrm{mmol} \mathrm{L}^{-1}(\mathrm{~N} /$ P 20). We observed a slight increase of cellular quotas in the mid-exponential phase of the growth curve for the total cyanopeptide concentration, total microcystins, and total cyclamides. The production of no particular cyanopeptide was favored depending on the growth stages and suggested synchronic production along with microcystins. Comparable results were obtained for the other growth conditions (N/P 2 and 40, Figure S13). Peak production in the mid-exponential phase was previously reported for microcystins, ${ }^{21,23,61}$ but only two studies considered the production of other cyanopeptides over the growth stages thus far and none of them have considered cyclamides. ${ }^{17,22}$ Carneiro et al. also observed synchronized production for microcystins and microginins but without significant change across the growth cycle of a Microcystis field isolate. ${ }^{17}$ On the other hand, Repka et al. observed peak production for microcystins in the midexponential phase while anabaenopeptin production peak later in the late stationary phase using Anabaena $90 .{ }^{22}$ Our data suggest that differences in production dynamics across the growth phases vary not only between genera but also between species. An improved understanding when cyanopeptides are produced and how they may covary will also facilitate hypotheses about the biological function of these complex molecules.

Nutrient Effects on Cyanopeptide Production Dynamics. We further investigated the effect of different nutrient concentrations on the cyanopeptide production dynamics for $M$. aeruginosa and D. flos-aquae. Across all experiments, we tested nutrient ranges from $0.5 \mu \mathrm{M}$ to $0.5 \mathrm{mM}$ phosphorous $\left(0.02-16 \mathrm{mgP} \mathrm{L}^{-1}\right)$ and $10 \mu \mathrm{M}$ to $1 \mathrm{mM}$ nitrogen $(0.7-71$ 
A. Total cyanopeptides

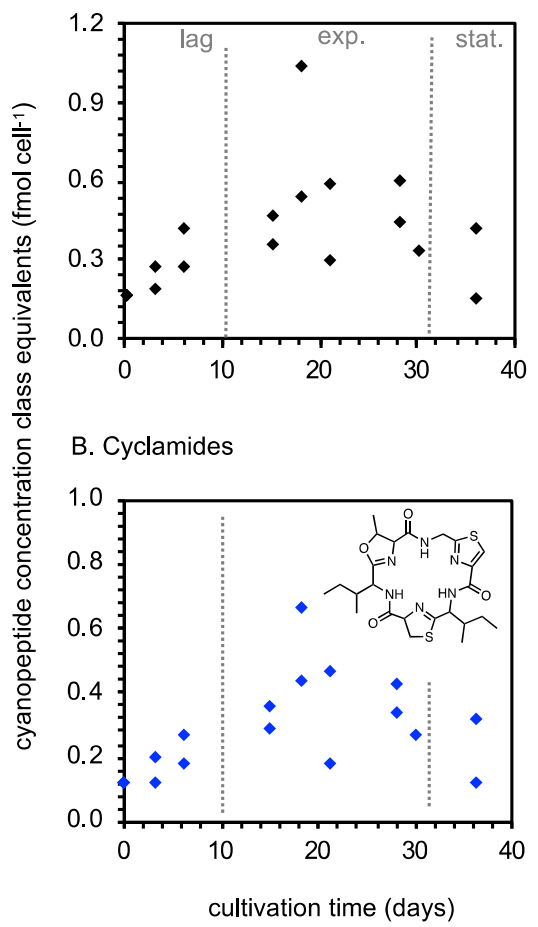

C. Microcystins

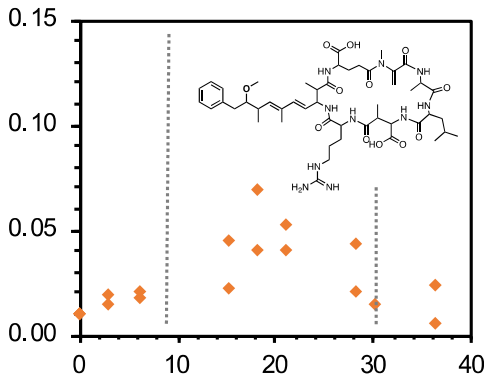

D. Cyanopeptolins

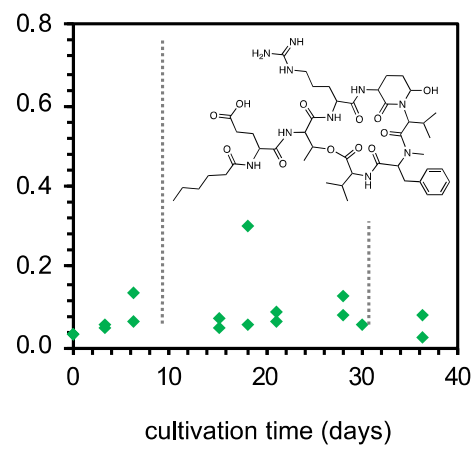

Figure 2. Cyanopeptide concentration per cell in class equivalents over the growth curve for M. aeruginosa for the total production of cyanopeptides (A) and by cyanopeptide class of cyclamides (B), microcystins (C), and cyanopeptolins (D). The shown chemical structures are representative compounds for each cyanopeptide class: aerucyclamide A, microcystin-LR, and cyanopeptolin A, but the shown concentration values represent the sum of all identified members for each class.

$\left.\operatorname{mgN~} L^{-1}\right)$. Data in Figure 3 show that the reduction of nutrients always reduced the growth rate $(\mu)$ and final cell
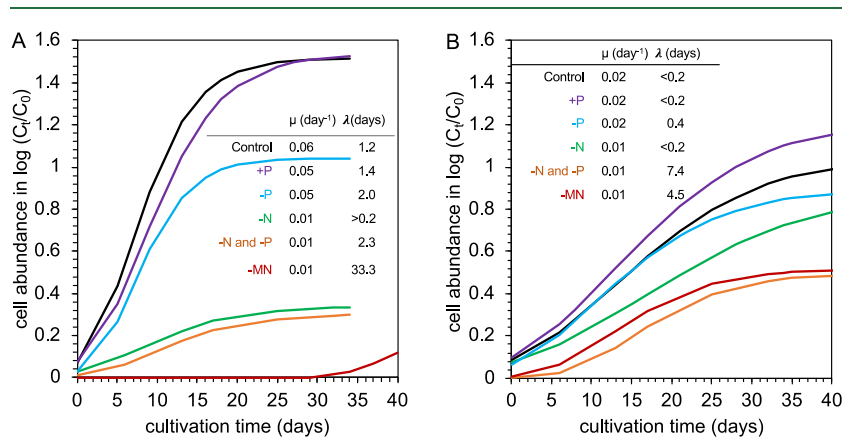

Figure 3. Fitted growth curves of (A) M. aeruginosa and (B) D. flosaquae as $\log$-normalized cell abundance $\left(\log C_{t} / C_{0}\right)$ for batch experiments in modified WC medium at six different nutrient concentrations, including the reference conditions with $1 \mathrm{mmol} \mathrm{N} \mathrm{L}$

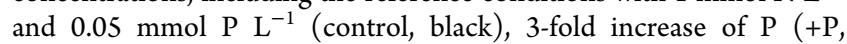
purple), 100-fold decrease of $\mathrm{P}(-\mathrm{P}$, blue), 100-fold decrease of $\mathrm{N}$ $(-\mathrm{N}$, green), 100 -fold decrease of $\mathrm{P}$ and $\mathrm{N}(-\mathrm{N}$ and $-\mathrm{P}$, orange $)$, and 100 -fold decrease of micronutrients $(-\mathrm{MN}$, red). The growth parameters obtained by fitting the Richard model are indicated with $\mu$ being the exponential growth rate per day and $\lambda$ being the lag time before exponential growth in days.

density $(A)$ for both species. For $M$. aeruginosa, the decrease of nitrogen alone and together with phosphorous significantly decrease the final cell density by $86 \%(p<0.0001)$ and the specific growth rate by $84 \%(p=0.025)$. The decrease of only phosphorous reduced these growth parameters to a lesser extent (by 33 and $22 \%$, respectively), suggesting that nitrogen was the most limiting growth factor for $M$. aeruginosa under these conditions. It has previously been shown that nitrogen limitation has a more severe effect on cyanobacterial growth, especially for non-nitrogen-fixing cyanobacteria such as $M$. aeruginosa. $^{62}$ Also, cyanobacteria can adapt to reduced phosphorous availability in surface waters by upregulating specific pathways. Upregulation of transporters responsible for phosphorous storage has been reported to facilitate phosphate storage. ${ }^{63,64}$ It was also reported that phosphate limitations can upregulate sulfate-binding protein and permease protein synthesis, suggesting that cyanobacteria can switch to sulfolipids in place of phospholipids to reduce cellular phosphorus quotas. ${ }^{32}$ When micronutrients were reduced, we observed a drastic reduction of growth, an increased lag phase to 33 days, and color change to yellow as a sign of cell apoptosis for M. aeruginosa. While the effects on D. flos-aquae were less severe, micronutrient reduction also reduced the final cell density by $52 \%$ and the growth rate by $23 \%$. Trace metals are essential to living organisms as cofactors and phototrophic organisms such as cyanobacteria have relatively high trace metal requirements for optimal growth since metal cofactors are part of the photosynthetic apparatus. ${ }^{65}$

Nutrient reduction is not only expected to affect cell proliferation but also the production of secondary metabolites. Here, we investigated the effect of nutrient limitation on cyanopeptide production by analyzing biomass in the late exponential phase (or at day 40 for $M$. aeruginosa under reduced micronutrient conditions where the stationary phase was not reached). Data in Figure 4 show the total cyanopeptide concentrations in nmol class equivalents normalized to the dry weight of analyzed biomass. The total production of cyanopeptides ranged in the hundreds of nmol $\mathrm{mg}_{\mathrm{dry}-\mathrm{wt}}{ }^{-1}$ for $M$. aeruginosa and in the thousands of nmol 

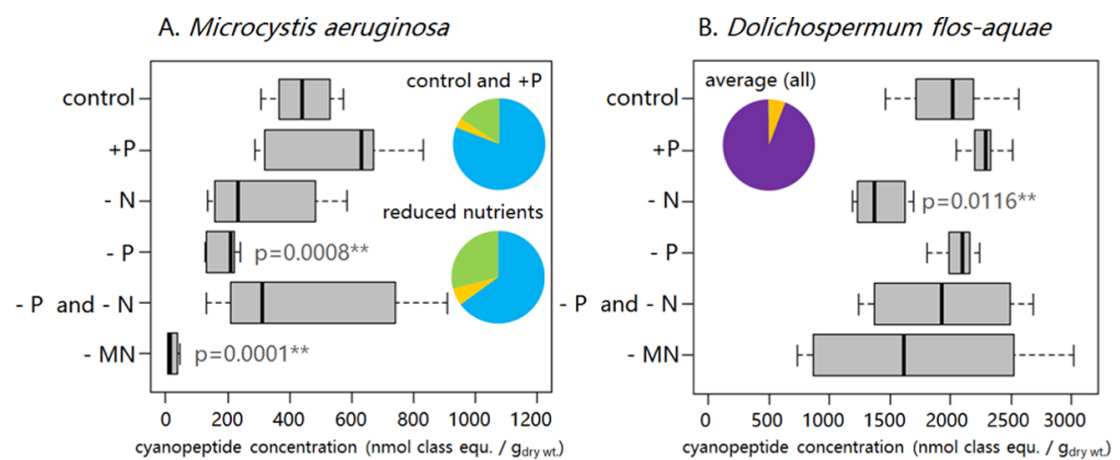

Figure 4. Total cyanopeptide concentration in nmol class equivalent per dry weight for (A) M. aeruginosa PCC7806 and (B) D. flos-aquae under six different nutrient conditions, including the reference conditions with $1 \mathrm{mmol} \mathrm{N} \mathrm{L}{ }^{-1}$ and $0.05 \mathrm{mmol} \mathrm{P} \mathrm{L}{ }^{-1}$ and enhanced total phosphorous $(+\mathrm{P}$, by factor 3), reduced total phosphorous ( $-\mathrm{P}$, by factor 100), reduced total nitrogen ( $-\mathrm{N}$, by factor 100$)$, reduced total phosphorous and nitrogen (both $-\mathrm{N}$ and $-\mathrm{P}$ by factor 100), and reduced micronutrient concentration ( $-\mathrm{MN}$ by factor 100) relative to the control conditions (WC medium). The pie charts represent the cyanopeptide profile with relative contribution of cyclamides (blue), cyanopeptolins (green), microcystins (yellow), and anabaenopeptins (purple). $p$-Values of $t$-test from comparison to the control conditions are listed. $*_{p}$-Value $<0.1$ and $* * p$-value $<$ 0.05 .

$\mathrm{mg}_{\mathrm{dry}-\mathrm{wt}}{ }^{-1}$ for D. flos-aquae. While reduction of nutrients always reduced growth significantly, only reduction of phosphorus and micronutrients from 50 to $0.5 \mu \mathrm{M}$ significantly reduced cyanopeptide production by $M$. aeruginosa ( $t$-test, $p=0.0008$ and 0.0001 , respectively). Tonk et al. also observed that the production rate by $M$. aeruginosa of microcystin-LR and three cyanopeptolins decreased when lowering phosphate availability from 3 to $0.03 \mu \mathrm{M}^{23}$ Our data demonstrates that this effects also holds for the production of the highly abundant cyclamides and is not apparent at higher $P$-availability (from 25 to $50 \mu \mathrm{M}$, Figure $1 \mathrm{~B}$ ). Under severe phosphorous limitation, upregulation of phosphorous transport by Microcystis may be carried out to the expense of cyanopeptide production as both processes are considered to be metabolically expensive. $^{63,64}$

While all conditions with reduced nutrient availability significantly reduced growth also for $D$. flos-aquae, only reduction of nitrogen significantly reduced cyanopeptide production. Previously, a negative effect of nitrogen reduction had only been reported for microcystin production. ${ }^{21,63,66,67}$ Here, we demonstrate that the same relationship holds true also for anabaenopeptins. These findings are consistent with the nitrogen requirements for cyanopeptide synthesis, as nitrogen is not only an essential nutrient needed by the enzymes involved in cyanopeptide production but is also a key building block of these $\mathrm{N}$-rich compounds $(\mathrm{C} / \mathrm{N}$ ratio of $4-$ 7). ${ }^{68}$ Furthermore, previous work demonstrated that reduced nitrogen availability resulted in a lower transcript abundance of the microcystin synthetase genes (mcyA-mcyE) for $M$. aeruginosa spp. ${ }^{32}$ We hypothesize that anabaenopeptin synthetase genes may be similarly regulated when nitrogen is limited. Reducing phosphorous availability to $0.5 \mu \mathrm{M}$ had no observable effect on the cyanopeptide production for $D$. flosaquae, which is in agreement with a previous study that reported an effect on anabaenopeptin production only at strong limitation at $0.1-1 \mu \mathrm{M}$ for Anabaena $90 .^{22}$ We observed that the cyanopeptide profile for D. flos-aquae remained rather constant across different nutrient conditions, with anabaenopeptins being the dominant peptide family (94\%), followed by microcystins $(6 \%)$ and a minor contribution of cyanopeptolins $(<1 \%)$ (pie chart insert in Figure 4B). The cyanopeptide profile of $M$. aeruginosa changed under nutrient limiting conditions and we observed a consistent increase of cyanopeptolins (from 16 to $29 \%$ ) and a decrease of cyclamides (from 80 to $65 \%$ ) while the contribution of microcystins remained comparable (4-6\%, pie chart inserts in Figure 4A).

\section{IMPLICATIONS}

Thus far, the knowledge on production dynamics of cyanopeptide beyond microcystins remains limited. Here, we demonstrate that cellular quotas of $M$. aeruginosa (PCC7806) were dominated by cyclamides, a class of cyanopeptide that has not been included in studies of production dynamics before. The production of no particular cyanopeptide was favored depending on the growth stages and suggested synchronic production along with microcystins. The results demonstrate that $M$. aeruginosa maintained similar relative concentrations of all cyanopeptides across different peptide classes. We can hypothesize the reason why cyanobacteria producing different cyanopeptides is not related to requirements that change during the growth cycle. Our observations further suggest that $M$. aeruginosa and D. flos-aquae respond differently to reduced phosphorous, nitrogen, and micronutrient availability, not only regarding their growth behavior but also regarding their cyanopeptide production. Finding the cause of the different effects of nutrient conditions on cyanopeptide production dynamics between species remains challenging because the underlying motivation why cyanobacteria produce these metabolites in the first place remains poorly understood. Our data suggest that the production dynamics of less studied cyanopeptides are in part comparable to those of the wellknown microcystins, and one can hypothesize that distinct cyanopeptides serve different functions for $D$. flos-aquae, rich in anabaenopeptins, and $M$. aeruginosa, rich in cyclamides and cyanopeptolins.

While the quantification of many cyanopeptides is not possible due to the lack of reference standard materials, the class-equivalent approach presented here determined concentrations more accurately than the more common microcystinLR equivalent approach. While the microcystin-LR equivalent approach is more widely available, the response in mass spectrometry analysis can vary up to 6-fold for other cyanopeptides, which translates into false quantification of the same magnitude. The class-equivalent approach provides a more accurate representation of the absolute and relative contribution of individual cyanopeptides and peptide classes. 
From the large target list of more than 700 structurally known cyanopeptides, we herein identified 24 different cyanopeptides produced by these two common bloom-forming strains; $M$. aeruginosa and $D$. flos-aquae. These less studied cyanopeptides should be prioritized and commercially reference standards should be made available to encourage more studies on their occurrence in blooms, persistence, and potential toxicity.

\section{ASSOCIATED CONTENT}

\section{SI Supporting Information}

The Supporting Information is available free of charge at https://pubs.acs.org/doi/10.1021/acs.est.9b07334.

Cyanopeptide suspect list, fragmentation spectra, and details on culturing and analytical details (PDF)

\section{AUTHOR INFORMATION}

\section{Corresponding Author}

Elisabeth M.-L. Janssen - Department of Environmental Chemistry, Swiss Federal Institute of Aquatic Science and Technology (Eawag), 8600 Dübendorf, Switzerland; (1) orcid.org/0000-0002-5475-6730; Phone: +41 58765 5802; Email: elisabeth.janssen@eawag.ch

\section{Author \\ Regiane Natumi - Department of Environmental Chemistry, Swiss Federal Institute of Aquatic Science and Technology (Eawag), 8600 Dübendorf, Switzerland}

Complete contact information is available at: https://pubs.acs.org/10.1021/acs.est.9b07334

\section{Notes}

The authors declare no competing financial interest.

\section{ACKNOWLEDGMENTS}

Funding of the Marie Curie Innovative Training Network "Natural Toxins and Drinking Water Quality-From Source to Tap (NaToxAq)" (Grant No. 722493) by the European Commission is gratefully acknowledged. We thank Martin Jones for improving the cyanopeptide database and valuable discussions, Marta Reyes and Francesco Pomati for culturing support, Evelyn Vonwyl and Birgit Beck for experimental assistance, and Jennifer Schollée for data analysis support.

\section{REFERENCES}

(1) Preece, E. P.; Hardy, F. J.; Moore, B. C.; Bryan, M. A review of microcystin detections in Estuarine and Marine waters: Environmental implications and human health risk. Harmful Algae 2017, 61, $31-45$.

(2) Paerl, H. W.; Hall, N. S.; Calandrino, E. S. Controlling harmful cyanobacterial blooms in a world experiencing anthropogenic and climatic-induced change. Sci. Total Environ. 2011, 409, 1739-1745.

(3) O’Neil, J. M.; Davis, T. W.; Burford, M. A.; Gobler, C. J. The rise of harmful cyanobacteria blooms: The potential roles of eutrophication and climate change. Harmful Algae 2012, 14, 313-334.

(4) Carmichael, W. W.; Azevedo, S. M. F. O.; An, J. S.; Molica, R. J. R.; Jochimsen, E. M.; Lau, S.; Rinehart, K. L.; Shaw, G. R.; Eaglesham, G. K. Human fatalities from cyanobacteria: Chemical and biological evidence for cyanotoxins. Environ. Health Perspect. 2001, 109, 663668.

(5) Pouria, S.; de Andrade, A.; Barbosa, J.; Cavalcanti, R. L.; Barreto, V. T. S.; Ward, C. J.; Preiser, W.; Poon, G. K.; Neild, G. H.; Codd, G. A. Fatal microcystin intoxication in haemodialysis unit in Caruaru, Brazil. Lancet 1998, 352, 21-26.
(6) Konst, H.; Mckercher, P. D.; Gorham, P. R.; Robertson, A.; Howell, J. Symptoms and pathology produced by toxic Microcystis aeruginosa Nrc-1 in laboratory and domestic animals. Can. J. Comp. Med. Vet. Sci. 1965, 29, 221-228.

(7) Backer, L. C.; Landsberg, J. H.; Miller, M.; Keel, K.; Taylor, T. K. Canine cyanotoxin poisonings in the United States (1920s-2012): review of suspected and confirmed cases from three data sources. Toxins 2013, 5, 1597-1628.

(8) Ibelings, B. W.; Backer, L. C.; Kardinaal, W. E. A.; Chorus, I. Current approaches to cyanotoxin risk assessment and risk management around the globe. Harmful Algae 2014, 40, 63-74.

(9) Welker, M.; Brunke, M.; Preussel, K.; Lippert, I.; von Dohren, H. Diversity and distribution of Microcystis (Cyanobacteria) oligopeptide chemotypes from natural communities studied by single-colony mass spectrometry. Microbiology 2004, 150, 1785-1796.

(10) Beversdorf, L. J.; Weirich, C. A.; Bartlett, S. L.; Miller, T. R. Variable cyanobacterial toxin and metabolite profiles across six eutrophic lakes of differing physiochemical characteristics. Toxins 2017, 9, 62.

(11) Bogialli, S.; Bortolini, C.; Di Gangi, I. M.; Di Gregorio, F. N.; Lucentini, L.; Favaro, G.; Pastore, P. Liquid chromatography-high resolution mass spectrometric methods for the surveillance monitoring of cyanotoxins in freshwaters. Talanta 2017, 170, 322-330.

(12) Kurmayer, R.; Deng, L.; Entfellner, E. Role of toxic and bioactive secondary metabolites in colonization and bloom formation by filamentous cyanobacteria Planktothrix. Harmful Algae 2016, 54, $69-86$.

(13) Otten, T. G.; Paerl, H. W.; Dreher, T. W.; Kimmerer, W. J.; Parker, A. E. The molecular ecology of Microcystis sp blooms in the San Francisco Estuary. Environ. Microbiol. 2017, 19, 3619-3637.

(14) Le Manach, S.; Duval, C.; Marie, A.; Djediat, C.; Catherine, A.; Edery, M.; Bernard, C.; Marie, B. Global metabolomic characterizations of Microcystis spp. highlights clonal diversity in natural bloomforming populations and expands metabolite structural diversity. Front. Microbiol. 2019, 10, No. 791.

(15) Sanz, M.; Andreote, A. P. D.; Fiore, M. F.; Dorr, F. A.; Pinto, E. Structural characterization of new peptide variants produced by cyanobacteria from the Brazilian atlantic coastal forest using liquid chromatography coupled to quadrupole time-of-flight tandem mass spectrometry. Mar. Drugs 2015, 13, 3892-3919.

(16) Mazur-Marzec, H.; Bertos-Fortis, M.; Torunska-Sitarz, A.; Fidor, A.; Legrand, C. Chemical and genetic diversity of Nodularia spumigena from the Baltic Sea. Mar. Drugs 2016, 14, No. 209.

(17) Carneiro, R. L.; Dorr, F. A.; Dorr, F.; Bortoli, S.; Delherbe, N.; Vasquez, M.; Pinto, E. Co-occurrence of microcystin and microginin congeners in Brazilian strains of Microcystis sp. FEMS Microbiol. Ecol. 2012, 82, 692-702.

(18) Chorus, I.; Sivonen, K.; Codd, G. A.; Börner, T.; Von Doehren, H.; Welker, M.; Dittmann, E.; Claussner, Y.; Christopffersen, K.; Scober, E.; Utliken, H.; Rohrlack, T.; Lyck, S.; Visser, P. M.; Tonk, L.; Dietrich, D. R.; Hoeger, S. J.; Tandeau de Marsac, N.; Iteman, I.; Niesel, V.; Fastner, J.; Grummt, T.; Heinze, R.; Ferreira, A.-H.; Warming-Svendsen, T.; Flieger, I.; Wessel, G.; Rouhiainen, L.; Morrison, L. F. Toxic and Bioactive Peptides in CyanobacteriaPEPCY Report, 2006.

(19) Janssen, E. M. L. Cyanobacterial peptides beyond microcystins - a review on co-occurrence, toxicity, and challenges for risk assessment. Water Res. 2019, 151, 488-499.

(20) Beversdorf, L. J.; Rude, K.; Weirich, C. A.; Bartlett, S. L.; Seaman, M.; Kozik, C.; Biese, P.; Gosz, T.; Suha, M.; Stempa, C.; Shaw, C.; Hedman, C.; Piatt, J. J.; Miller, T. R. Analysis of cyanobacterial metabolites in surface and raw drinking waters reveals more than microcystin. Water Res. 2018, 140, 280-290.

(21) Lee, S. J.; Jang, M. H.; Kim, H. S.; Yoon, B. D.; Oh, H. M. Variation of microcystin content of Microcystis aeruginosa relative to medium N: P ratio and growth stage. J. Appl. Microbiol. 2000, 89, $323-329$.

(22) Repka, S.; Koivula, M.; Harjunpa, V.; Rouhiainen, L.; Sivonen, $\mathrm{K}$. Effects of phosphate and light on growth of and bioactive peptide 
production by the cyanobacterium Anabaena strain 90 and its anabaenopeptilide mutant. Appl. Environ. Microbiol. 2004, 70, 45514560.

(23) Tonk, L.; Welker, M.; Huisman, J.; Visser, P. M. Production of cyanopeptolins, anabaenopeptins, and microcystins by the harmful cyanobacteria Anabaena 90 and Microcystis PCC 7806. Harmful Algae 2009, 8, 219-224.

(24) Dai, R. H.; Wang, P. F.; Jia, P. L.; Zhang, Y.; Chu, X. C.; Wang, Y. F. A review on factors affecting microcystins production by algae in aquatic environments. World J. Microbiol. Biotechnol. 2016, 32, No. 51. (25) Dolman, A. M.; Rucker, J.; Pick, F. R.; Fastner, J.; Rohrlack, T.; Mischke, U.; Wiedner, C. Cyanobacteria and cyanotoxins: the influence of nitrogen versus phosphorus. PLoS One 2012, 7, No. e38757.

(26) Tromas, N.; Taranu, Z. E.; Martin, B. D.; Willis, A.; Fortin, N.; Greer, C. W.; Shapiro, B. J. Niche separation increases with Genetic distance among bloom-forming cyanobacteria. Front. Microbiol. 2018, 9, No. 438.

(27) Xie, L. Q.; Xie, P.; Li, S. X.; Tang, H. J.; Liu, H. The low TN: TP ratio, a cause or a result of Microcystis blooms? Water Res. 2003, 37, 2073-2080.

(28) Chia, M. A.; Jankowiak, J. G.; Kramer, B. J.; Goleski, J. A.; Huang, I.-S.; Zimba, P. V.; do Carmo Bittencourt-Oliveira, M.; Gobler, C. J. Succession and toxicity of Microcystis and Anabaena (Dolichospermum) blooms are controlled by nutrient-dependent allelopathic interactions. Harmful Algae 2018, 74, 67-77.

(29) Oh, H. M.; Lee, S. J.; Jang, M. H.; Yoon, B. D. Microcystin production by Microcystis aeruginosa in a phosphorus-limited chemostat. Appl. Environ. Microbiol. 2000, 66, 176-179.

(30) Pimentel, J. S. M.; Giani, A. Microcystin production and regulation under nutrient stress conditions in toxic Microcystis strains. Appl. Environ. Microbiol. 2014, 80, 5836-5843.

(31) Davis, T. W.; Berry, D. L.; Boyer, G. L.; Gobler, C. J. The effects of temperature and nutrients on the growth and dynamics of toxic and non-toxic strains of microcystis during cyanobacteria blooms. Harmful Algae 2009, 8, 715-725.

(32) Harke, M. J.; Gobler, C. J. Global Transcriptional responses of the toxic cyanobacterium, Microcystis aeruginosa, to nitrogen stress, phosphorus stress, and growth on organic matter. PLoS One 2013, 8, No. e69834.

(33) Yu, L.; Kong, F. X.; Zhang, M.; Yang, Z.; Shi, X. L.; Du, M. Y. The dynamics of Microcystis genotypes and microcystin production and associations with environmental factors during blooms in Lake Chaohu, China. Toxins 2014, 6, 3238-3257.

(34) Gobler, C. J.; Burkholder, J. M.; Davis, T. W.; Harke, M. J.; Johengen, T.; Stow, C. A.; Van de Waal, D. B. The dual role of nitrogen supply in controlling the growth and toxicity of cyanobacterial blooms. Harmful Algae 2016, 54, 87-97.

(35) Van de Waal, D. B.; Verspagen, J. M. H.; Lurling, M.; Van Donk, E.; Visser, P. M.; Huisman, J. The ecological stoichiometry of toxins produced by harmful cyanobacteria: an experimental test of the carbon-nutrient balance hypothesis. Ecol. Lett. 2009, 12, 1326-1335.

(36) Vézie, C.; Rapala, J.; Vaitomaa, J.; Seitsonen, J.; Sivonen, K. Effect of nitrogen and phosphorus on growth of toxic and nontoxic Microcystis strains and on intracellular microcystin concentrations. Microb. Ecol. 2002, 43, 443-454.

(37) Portmann, C.; Blom, J. F.; Gademann, K.; Juttner, F. Aerucyclamides A and B: Isolation and synthesis of toxic ribosomal heterocyclic peptides from the cyanobacterium Microcystis aeruginosa PCC 7806. J. Nat. Prod. 2008, 71, 1193-1196.

(38) Guillard, R. R.; Lorenzen, C. J. Yellow-green algae with chlorophyllide C. J. Phycol. 1972, 8, 10-14.

(39) Richards, F. J. A flexible growth function for empirical use. J. Exp. Bot. 1959, 10, 290-300.

(40) Schymanski, E. L.; Jeon, J.; Gulde, R.; Fenner, K.; Ruff, M.; Singer, H. P.; Hollender, J. Identifying small molecules via high resolution mass spectrometry: communicating confidence. Environ. Sci. Technol. 2014, 48, 2097-2098.
(41) Stravs, M. A.; Schymanski, E. L.; Singer, H. P.; Hollender, J. Automatic recalibration and processing of tandem mass spectra using formula annotation. J. Mass Spectrom. 2013, 48, 89-99.

(42) Schollee, J. E. MSMSsim: functions for processing HRMS2 spectra from output from RMassBank, mainly for calculating spectral similarity, 2017. https://github.com/dutchjes/MSMSsim.

(43) RStudio. Integarted development for R; RStudio, Inc.: Boston, MA, 2019. http://www.rstudio.com/2019.

(44) Chambers, M. C.; Maclean, B.; Burke, R.; Amodei, D.; Ruderman, D. L.; Neumann, S.; Gatto, L.; Fischer, B.; Pratt, B.; Egertson, J.; Hoff, K.; Kessner, D.; Tasman, N.; Shulman, N.; Frewen, B.; Baker, T. A.; Brusniak, M. Y.; Paulse, C.; Creasy, D.; Flashner, L.; Kani, K.; Moulding, C.; Seymour, S. L.; Nuwaysir, L. M.; Lefebvre, B.; Kuhlmann, F.; Roark, J.; Rainer, P.; Detlev, S.; Hemenway, T.; Huhmer, A.; Langridge, J.; Connolly, B.; Chadick, T.; Holly, K.; Eckels, J.; Deutsch, E. W.; Moritz, R. L.; Katz, J. E.; Agus, D. B.; MacCoss, M.; Tabb, D. L.; Mallick, P. A cross-platform toolkit for mass spectrometry and proteomics. Nat. Biotechnol. 2012, 30, $918-$ 920.

(45) Martin, C.; Oberer, L.; Ino, T.; Konig, W. A.; Busch, M.; Weckesser, J. Cyanopeptolins, new depsipeptides from the cyanobacterium Microcystis sp. PCC 7806. J. Antibiot. 1993, 46, 1550-6.

(46) Bister, B.; Keller, S.; Baumann Heike, I.; Nicholson, G.; Weist, S.; Jung, G.; Sussmuth Roderich, D.; Juttner, F. Cyanopeptolin 963A, a chymotrypsin inhibitor of Microcystis PCC 7806. J. Nat. Prod. 2004, $67,1755-1757$.

(47) Downing, T. G.; Sember, C. S.; Gehringer, M. M.; Leukes, W. Medium N: P ratios and specific growth rate comodulate microcystin and protein content in Microcystis aeruginosa PCC7806 and M aeruginosa UV027. Microb. Ecol. 2005, 49, 468-473.

(48) Portmann, C.; Blom, J. F.; Kaiser, M.; Brun, R.; Juttner, F.; Gademann, $\mathrm{K}$. Isolation of aerucyclamides $\mathrm{C}$ and $\mathrm{D}$ and structure revision of microcyclamide 7806A: Heterocyclic ribosomal peptides from Microcystis aeruginosa PCC 7806 and their antiparasite evaluation. J. Nat. Prod. 2008, 71, 1891-1896.

(49) Botes, D. P.; Wessels, P. L.; Kruger, H.; Runnegar, M. T. C.; Santikarn, S.; Smith, R. J.; Barna, J. C. J.; Williams, D. H. Structural studies on cyanoginosin-Lr, cyanoginosin-Yr, cyanoginosin-Ya and -cyanoginosin-Ym, peptide toxins from Microcystis aeruginosa. J. Chem. Soc., Perkin Trans. 1 1985, 2747-2748.

(50) Sano, T.; Kaya, K. Oscillamide-Y, a Chymotrypsin inhibitor from toxic Oscillatoria agardhii. Tetrahedron Lett. 1995, 36, 59335936.

(51) Harada, K.; Fujii, K.; Shimada, T.; Suzuki, M.; Sano, H.; Adachi, K.; Carmichael, W. W. 2 Cyclic-peptides, anabaenopeptins, a 3rd group of bioactive compounds from the cyanobacterium Anabaena flos-aquae Nrc-525-17. Tetrahedron Lett. 1995, 36, 15111514.

(52) Murakami, M.; Shin, H. J.; Matsuda, H.; Ishida, K.; Yamaguchi, $\mathrm{K}$. A cyclic peptide, anabaenopeptin B, from the cyanobacterium Oscillatoria agardhii. Phytochemistry 1997, 44, 449-452.

(53) Di Gregorio, F. N.; Bogialli, S.; Ferretti, E.; Lucentini, L. First evidence of MC-HtyR associated to a Plankthothrix rubescens blooming in an Italian lake based on a LC-MS method for routinely analysis of twelve microcystins in freshwaters. Microchem. J. 2017, 130, 329-335.

(54) Sano, T.; Beattie, K. A.; Codd, G. A.; Kaya, K. Two (Z)dehydrobutyrine-containing microcystins from a hepatotoxic bloom of Oscillatoria agardhii from Soulseat Loch, Scotland. J. Nat. Prod. 1998, 61, 851-853.

(55) Rapala, J.; Sivonen, K.; Lyra, C.; Niemela, S. I. Variation of microcystins, cyanobacterial hepatotoxins, in Anabaena spp. as a function of growth stimuli. Appl. Environ. Microbiol. 1997, 63, 22062212.

(56) Wiedner, C.; Visser, P. M.; Fastner, J.; Metcalf, J. S.; Codd, G. A.; Mur, L. R. Effects of light on the microcystin content of Microcystis strain PCC 7806. Appl. Environ. Microbiol. 2003, 69, 1475-1481.

(57) Saxton, M. A.; Arnold, R.; Bourbonniere, R. A.; McKay, R. M. L.; Wilhelm, S. W. Plasticity of total and intracellular phosphorus 
quotas in Microcystis aeruginosa cultures and Lake Erie algal assemblages. Front. Microbiol. 2012, 3, No. 3.

(58) Kuniyoshi, T. M.; Sevilla, E.; Bes, M. T.; Fillat, M. F.; Peleato, M. L. Phosphate deficiency (N/P 40:1) induces mcyD transcription and microcystin synthesis in Microcystis aeruginosa PCC7806. Plant Physiol. Biochem. 2013, 65, 120-124.

(59) Krüger, T.; Holzel, N.; Luckas, B. Influence of cultivation parameters on growth and microcystin production of Microcystis aeruginosa (cyanophyceae) isolated from Lake Chao (China). Microb. Ecol. 2012, 63, 199-209.

(60) Jähnichen, S.; Long, B. M.; Petzoldt, T. Microcystin production by Microcystis aeruginosa: Direct regulation by multiple environmental factors. Harmful Algae 2011, 12, 95-104.

(61) Watanabe, M. F.; Harada, K. I.; Matsuura, K.; Watanabe, M.; Suzuki, M. Heptapeptide toxin production during the batch culture of two Microcystis species (cyanobacteria). J. Appl. Phycol. 1989, 1, 161165.

(62) Jankowiak, J.; Hattenrath-Lehmann, T.; Kramer, B. J.; Ladds, M.; Gobler, C. J. Deciphering the effects of nitrogen, phosphorus, and temperature on cyanobacterial bloom intensification, diversity, and toxicity in western Lake Erie. Limnol. Oceanogr. 2019, 64, 1347-1370.

(63) Harke, M. J.; Davis, T. W.; Watson, S. B.; Gobler, C. J. Nutrient-controlled niche differentiation of western Lake Erie cyanobacterial populations revealed via metatranscriptomic surveys. Environ. Sci. Technol. 2016, 50, 604-615.

(64) Wan, L. L.; Chen, X. Y.; Deng, Q. H.; Yang, L.; Li, X. W.; Zhang, J. Y.; Song, C. L.; Zhou, Y. Y.; Cao, X. Y. Phosphorus strategy in bloom-forming cyanobacteria (Dolichospermum and Microcystis) and its role in their succession. Harmful Algae 2019, 84, 46-55.

(65) Facey, J. A.; Apte, S. C.; Mitrovic, S. M. A Review of the effect of trace metals on freshwater cyanobacterial growth and toxin production. Toxins 2019, 11, No. 643.

(66) Long, B. M.; Jones, G. J.; Orr, P. T. Cellular microcystin content in N-limited Microcystis aeruginosa can be predicted from growth rate. Appl. Environ. Microbiol. 2001, 67, 278-283.

(67) Horst, G. P.; Sarnelle, O.; White, J. D.; Hamilton, S. K.; Kaul, R. B.; Bressie, J. D. Nitrogen availability increases the toxin quota of a harmful cyanobacterium, Microcystis aeruginosa. Water Res. 2014, 54, 188-198.

(68) Tillett, D.; Dittmann, E.; Erhard, M.; von Döhren, H.; Borner, T.; Neilan, B. A. Structural organization of microcystin biosynthesis in Microcystis aeruginosa PCC7806: an integrated peptide-polyketide synthetase system. Chem. Biol. 2000, 7, 753-764. 